doi: $10.1016 / j$.annepidem.2006.04.008

Copyright (c) 2006 Elsevier Inc. All rights reserved.

\title{
The Importance of Estimating Selection Bias on Prevalence Estimates Shortly After a Disaster
}

\section{Linda Grievink PhD ${ }^{a}{ }^{*}$, Peter G. van der Velden PhD ${ }^{a}$, C. Joris Yzermans PhD $^{a}$, Jan Roorda MSc ${ }^{a}$ and Rebecca K. Stellato MS ${ }^{a}$}

${ }^{a}$ From the Centre for Environmental Health Research, National Institute for Public Health and the Environment, Bilthoven (L.G., R.K.S.); Institute for Psychotrauma, Zaltbommel (P.G.v.d.V.); Netherlands Institute for Health Services Research, Utrecht (C.J.Y.); and Regional Health Authority Twente, Enschede, The Netherlands (J.R.)

Received 29 December 2005; accepted 31 March 2006. Available online 1 August 2006.

\footnotetext{
* Address correspondence to: Linda Grievink, PhD, RIVM-MGO (Pb 10), PO Box 1, 3720 BA Bilthoven, The Netherlands. Tel.: +31-30-274-4533; fax: +31-30-2744451.
}

\section{Purpose}

The aim was to study selective participation and its effect on prevalence estimates in a health survey of affected residents 3 weeks after a man-made disaster in The Netherlands (May 13, 2000).

\section{Methods}

All affected adult residents were invited to participate. Survey (questionnaire) data were combined with electronic medical records of residents' general practitioners (GPs). Data for demographics, relocation, utilization, and morbidity 1 year predisaster and 1 year postdisaster were used.

\section{Results}

The survey participation rate was $26 \%(\mathrm{~N}=1171)$. Women (odds ratio [OR], $1.46 ; 95 \%$ confidence interval $[\mathrm{CI}], 1.28-1.67)$, those living with a partner (OR, $2.00 ; 95 \% \mathrm{CI}, 1.72-2.33)$, those aged 45 to 64 years (OR, $2.00 ; 95 \% \mathrm{CI}, 1.59-$ $2.52)$, and immigrants (OR, $1.50 ; 95 \% \mathrm{CI}, 1.30-1.74)$ were more likely to participate. Participation rate was not affected by relocation because of the disaster. Participants in the survey consulted their GPs for health problems in the year before and after the disaster more often than nonparticipants. Although there was selective participation, multiple imputation barely affected prevalence estimates of health problems in the survey 3 weeks postdisaster.

\section{Conclusions}

Estimating actual selection bias in disaster studies gives better information about the study representativeness. This is important for policy making and providing effective health care. 
Annals of Epidemiology Volume 16, Issue 10 , October 2006, Pages 782-788

Key words: Disasters; Health Surveys; Imputation; Selection Bias; Survivors

Abbreviations: $\mathrm{CI}$, confidence interval; $\mathrm{EMR}$, electronic medical records (of general practitioner); GP, general practitioner; IAC, Information and Advice Center; ICPC, International Classification of Primary Care; OR, odds ratio

\section{Introduction}

In the aftermath of disasters, both short- and long-term health problems have been reported, such as feelings of anxiety or depression, severe sleeping difficulties, medically unexplained physical symptoms, and posttraumatic stress disorder 1, 2, 3, 4 and 5. Representative prevalence estimates of these health problems are needed after disasters to adequately organize health care for those who need professional help. Policy makers and health care providers need to know whether, and to what extent, an increase in use of health care facilities can be expected (6).

In the wake of the chaos that follows a disaster, it often is very difficult to obtain a representative sample. In addition, apart from material losses and injuries, there are no objective criteria to define who is a victim and who is not, making it difficult to create a methodologically sound sample. Nearly half the health surveys after disasters do not report a participation rate (4), prompting one to question whether participants in those surveys are representative of all survivors. It is common knowledge that representativeness of health surveys can be affected by selection in demographic and health factors. Shortly after disasters, disasterrelated experiences additionally might contribute to selective participation. How these experiences influence participation is unknown. One may speculate that survivors who were highly affected by the disaster or had high levels of postdisaster distress would be more motivated to participate in the health survey than survivors who were less affected. Conversely, highly exposed or distressed survivors could be less likely to respond because they do not want to be reminded of the stressful event.

Determining selective participation with regard to demographic-, health-, and disaster-related factors is important, but understanding whether that selection leads to actual bias in the outcome measures in a survey is essential for policy makers and health care providers. To our knowledge, none of the health studies after disasters presents information on the selection of adult survivors on the basis of health characteristics and disaster experiences, let alone the effect of the selection on outcome measures. Investigators of the few longitudinal studies that had predisaster data and described the impact of the disaster on postdisaster attrition rate did not comment on the representativeness of respondents 7,8 and 9.

To investigate selective participation and its potential bias on prevalence estimates of health problems in residents in a survey 3 weeks after a man-made disaster, we had the unique opportunity to combine these survey data with predisaster and postdisaster data retrieved from residents' general practitioners (GPs). The direction of the selective participation was studied with respect to demographics, disaster experience, use of the GP, and health problems presented to the GP. Furthermore, we used multiple imputation to examine the magnitude of selection bias on prevalence estimates of self-reported health problems. 


\section{Methods}

On May 13, 2000, a firework storage facility exploded in a residential area of Enschede, The Netherlands. The explosion and subsequent fires killed 23 persons, more than 900 people were injured, and about 500 homes were destroyed. The Dutch government declared this a national disaster and the Ministry of Health, Welfare, and Sports supported the regional authorities and launched a larger health care program especially designed for the survivors (11).

\section{Study Designs}

One component of the government program was a health survey performed 2.5 to 3.5 weeks after the disaster (12). All adult residents of the disaster area were personally invited by letter to participate in the study, and several announcements were made through local media. Participants completed a questionnaire regarding disaster experiences and physical and psychological health 6, 11 and 12. The Medical Ethical Testing Committee (TNO-Leiden, The Netherlands) approved the study protocol of the survey.

Another aspect of the government program was surveillance of health problems by using the electronic medical records (EMRs) in general practices. Use of these EMRs also enabled collection of predisaster data. In the Dutch health care system, each citizen is obliged to register with one GP, who functions as a gatekeeper to medical specialists (13). All GPs in the city of Enschede were invited to participate in the study. Sixteen of $60 \mathrm{GPs}(27 \%)$ did not participate because of a lack of survivors in their practice $(n=9)$, lack of an electronic registration system $(n=$ 1 ), or fear of increased workload because of participation $(n=6)$. Patients were informed of the participation of their GP in this health study; no patient objected to the use of their data for surveillance.

The program also included the registry of affected residents in a database of the Information and Advice Center (IAC). For this report, we combined the three databases through a unique personal identification number, following the privacy directives of the Dutch Data Protection Authority.

\section{Study Population}

Because survivors are difficult to define and the denominator usually is unclear in the direct aftermath of disasters, we focus on only adult residents of the official disaster area designated by the municipality. All adult residents $(\geq 18$ years at the time of the disaster) living in the disaster area were registered with the IAC ( $n=$ 4456).

Of 4456 eligible residents, 1171 completed a questionnaire (26\%). We compared these participants with the 3285 nonparticipating eligible residents. GP data for the full year before and after the disaster were available for 2897 of the 4456 affected residents $(65 \%)$.

\section{Measures}

\section{Demographic Variables}

Sex, age categories, family situation, and immigrant status (first or second generation versus native Dutch) were available for all affected residents from the 
IAC database. Serious damage to the house resulting in relocation was used as a measurement of disaster experience.

\section{Survey Data}

Data were collected by using a self-administered questionnaire consisting of validated instruments. For this report, we selected health problems frequently found after disasters: functional limitations in daily life caused by physical and emotional problems (RAND-36-item Health Survey [14]), severe sleeping difficulties (Groninger Sleep Quality Scale [15]), intrusion and avoidance reactions or posttraumatic stress symptoms (Impact of Event Scale 16, 17 and 18), and anxiety and depression symptoms (Symptom Check List-90 19 and 20).

\section{GP Data}

Data were extracted from the EMR of the GPs in Enschede (1 year before and after the disaster). Symptoms and diagnoses were classified according the International Classification of Primary Care, which is compatible with the International Classification of Diseases, 10th Revision (21). These symptoms and diagnoses were combined in 15 clusters (13): medically unexplained physical symptoms, chronic diseases, weight/eating/drinking problems, medication side effects, injury, headache, psychological problems, musculoskeletal problems, respiratory problems, skin problems, glandular problems, gastrointestinal problems, eye problems, ear problems, and urinary tract problems. Clusters were dichotomized into the presence (one or more) or absence of symptoms/diagnoses. We included all clusters in analyses because we had no indication from the literature that survivors with specific symptoms would be more or less likely to participate. In addition, type of insurance (public or private) was available as a proxy for socioeconomic status. Contact with the GP (one or more visits in a year) and more than average contact with the GP (six contacts per year on average in The Netherlands [22]) were determined from EMRs.

\section{Data Analysis}

To examine patterns in selective participation, participants of the survey were compared with nonparticipants for demographics, relocation, type of insurance, use of the GP, and health problems in a cluster 1 year predisaster and 1 year postdisaster. Because we were interested in identifying all possible predictors of nonresponse, we examined only crude odds ratios (ORs).

To study the effect of selective participation on the magnitude of prevalence estimates, we used multiple imputation (23) to "fill in" values for self-reported health problems (role limitations, sleep difficulty, intrusion and avoidance reactions, anxiety, and depressive symptoms) for nonresponders. Multiple imputation makes use of intercorrelations of variables from nonmissing data to estimate plausible values for data that are missing because of either survey or item nonresponse. We applied an adapted version of predictive mean matching (24) by using an SAS macro that makes partial use of the SAS (version 8.2; SAS Institute, Cary, NC) multiple imputation procedure. We generated five data sets: in each data set, nonmissing data are identical, but imputed values for missing data varied from one data set to another (25). Variables used in the imputation model were the outcomes of interest (self-reported health problems), demographics, relocation, GP use, and clusters of health problems 1 year predisaster and 1 year postdisaster. Imputed data sets were analyzed separately, and results were combined by sing the MIANALYZE procedure in SAS to produce valid confidence intervals (CIs). 
We expect that future disaster studies will at least have access to demographic data for survivors from the Census/Registry Office 9 and 10. However, it is unlikely that most studies will have access to complete GP data before and after the disaster. Therefore, we examined whether imputation with demographics only was adequate for estimating the bias. This was done by imputing prevalence estimates a second time with only demographic data and comparing results with those of the imputation model with both demographic and GP data.

\section{Results}

Participation rate in the health survey was $26 \%(N=1171)$. Table 1 lists crude differences in participation rates for demographic variables. Compared with nonparticipants, survey participants were more likely to be women, aged between 25 and 44 or 45 and 64 years of age, live with a partner, be a single parent, and be of immigrant background. Participation rate was not affected by relocation caused by the disaster. 
Table 1.

Demographic characteristics of participants and nonparticipants in the health survey for the entire cohort of affected residents in the fireworks disaster in Enschede, The Netherlands (May 13, 2000)

\begin{tabular}{|c|c|c|c|c|}
\hline & $\begin{array}{l}\text { Participants N } \\
=1171\end{array}$ & $\begin{array}{l}\text { Nonparticipants } \mathbf{N} \\
=3285\end{array}$ & $\begin{array}{l}\text { Odds } \\
\text { ratio }^{a}\end{array}$ & $\begin{array}{l}95 \% \text { Confidence } \\
\text { interval }\end{array}$ \\
\hline \multicolumn{5}{|l|}{ Sex } \\
\hline Male & $525(44.8)$ & $1783(54.3)$ & 1.00 & \\
\hline Female & $646(55.2)$ & $1502(45.7)$ & 1.46 & $1.28-1.67$ \\
\hline \multicolumn{5}{|l|}{ Age (years) } \\
\hline $18-24$ & $125(10.7)$ & $748(22.8)$ & 0.63 & $0.48-0.83$ \\
\hline $25-44$ & $522(44.6)$ & 1311 (39.9) & 1.50 & $1.20-1.87$ \\
\hline $45-64$ & $396(33.8)$ & $744(22.6)$ & 2.00 & $1.59-2.52$ \\
\hline $65+$ & $128(10.9)$ & $482(14.7)$ & 1.00 & \\
\hline \multicolumn{5}{|l|}{ Family situation } \\
\hline Child living with parents & $16(1.5)$ & $122(4.4)$ & 0.48 & $0.28-0.81$ \\
\hline Single parent & $59(5.5)$ & $144(5.2)$ & 1.49 & $1.08-2.06$ \\
\hline Living alone & $357(33.0)$ & $1300(47.3)$ & 1.00 & \\
\hline Living with partner ${ }^{\mathrm{b}}$ & $650(60.1)$ & $1184(43.1)$ & 2.00 & $1.72-2.33$ \\
\hline \multicolumn{5}{|l|}{ Immigrant status } \\
\hline Immigrant & $368(31.5)$ & $765(23.4)$ & 1.50 & $1.30-1.74$ \\
\hline Native Dutch & $801(68.5)$ & $2504(76.6)$ & 1.00 & \\
\hline \multicolumn{5}{|l|}{ Relocated } \\
\hline Yes & $291(24.9)$ & $784(23.9)$ & 1.05 & $0.90-1.23$ \\
\hline No & $880(75.1)$ & $2501(76.1)$ & 1.00 & \\
\hline
\end{tabular}

Values expressed as number (percent).

${ }^{a}$ Crude odds ratio is given for participants versus nonparticipants in the health survey; odds ratio greater than 1 means that participants with that demographic characteristic were more likely to participate.

${ }^{b}$ We were not able to distinguish between couples with or without children because of the structure of the data.

Survey participants consulted their GPs more often and had more than an average number of contacts than those who did not participate, both predisaster and postdisaster (Table 2). Because ORs for almost all 15 clusters of health problems in relation to participation were in the same direction, we list the six most prevalent clusters in Table 2. Survey participants consulted their GP more often for problems belonging to one of the clusters compared with nonparticipants both 1 year predisaster and 1 year postdisaster. Predisaster, ORs ranged from 1.23 (95\% CI, 1.01-1.51) for psychological problems to 1.78 (95\% CI, 1.49- 
Annals of Epidemiology Volume 16, Issue 10 , October 2006, Pages 782-788

2.11) for musculoskeletal problems. Postdisaster, ORs ranged from 1.32 ( $95 \% \mathrm{CI}$, 1.12-1.56) for chronic diseases to 2.19 (95\% CI, 1.87-2.57) for psychological problems. Some ORs increased noticeably 1 year postdisaster compared with 1 year predisaster, in particular, for having contact with a GP and having psychological problems. 


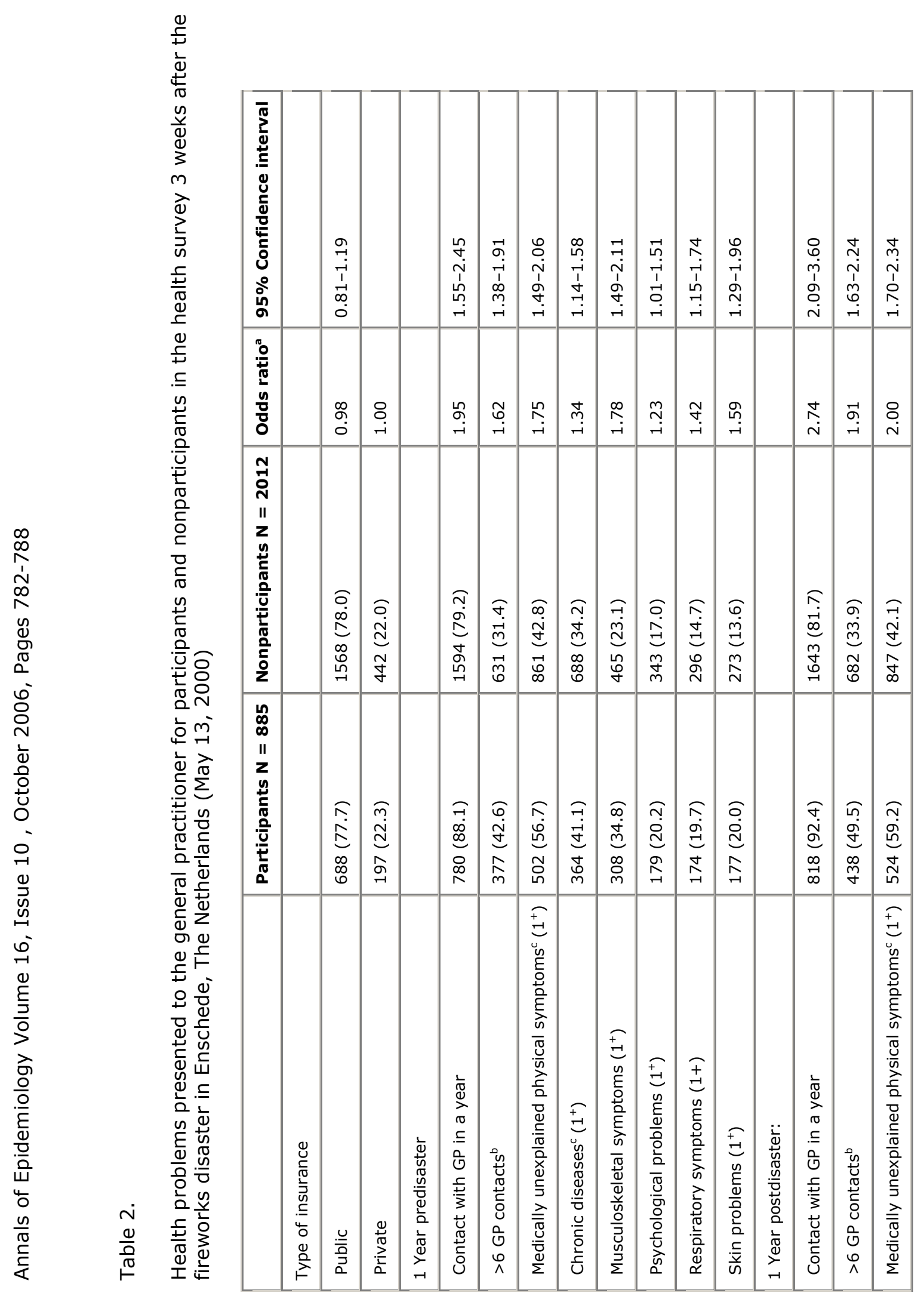


Annals of Epidemiology Volume 16, Issue 10 , October 2006, Pages 782-788

\begin{tabular}{|l|l|l|l|l|}
\hline & Participants N = 885 & Nonparticipants N = 2012 & Odds ratio $^{\mathbf{a}}$ & $\mathbf{9 5 \%}^{\circ}$ Confidence interval \\
\hline Chronic diseases $^{c}\left(1^{+}\right)$ & $347(39.2)$ & $660(32.8)$ & 1.32 & $1.12-1.56$ \\
\hline Musculoskeletal symptoms $\left(1^{+}\right)$ & $318(35.9)$ & $490(24.4)$ & 1.74 & $1.47-2.07$ \\
\hline Psychological problems $\left(1^{+}\right)$ & $476(53.8)$ & $698(34.7)$ & 2.19 & $1.87-2.57$ \\
\hline Respiratory symptoms $\left(1^{+}\right)$ & $164(20.0)$ & $270(16.4)$ & 1.47 & $1.19-1.82$ \\
\hline Skin problems $\left(1^{+}\right)$ & $185(20.9)$ & $263(13.1)$ & 1.76 & $1.43-2.16$ \\
\hline
\end{tabular}

Values expressed as number (percent). $1^{+}$means one ore more symptoms or diagnoses in that cluster reported by GP in 1 year.

$\mathrm{GP}=$ general practitioner.

${ }^{a}$ Crude odds ratio is given for participants versus nonparticipants in the health survey; odds ratio greater than 1 means that participants with one or more symptom (belonging to the cluster) were more likely to participate.

${ }^{b}$ Six GP contacts a year is the average in The Netherlands (23).

c Medically unexplained physical symptoms and chronic diseases cluster (partly) overlaps with the other clusters. 
Figure 1 shows that crude prevalence estimates of most health problems barely changed after imputation by using either demographic or demographic and GP data. However, the crude prevalence estimate for physical role limitations (62.5\%; 95\% CI, 59.4-65.6) was significantly higher than the prevalence estimate $(57.0 \% ; 95 \%$ CI, 54.8-59.2) after imputation for GP and demographic data.

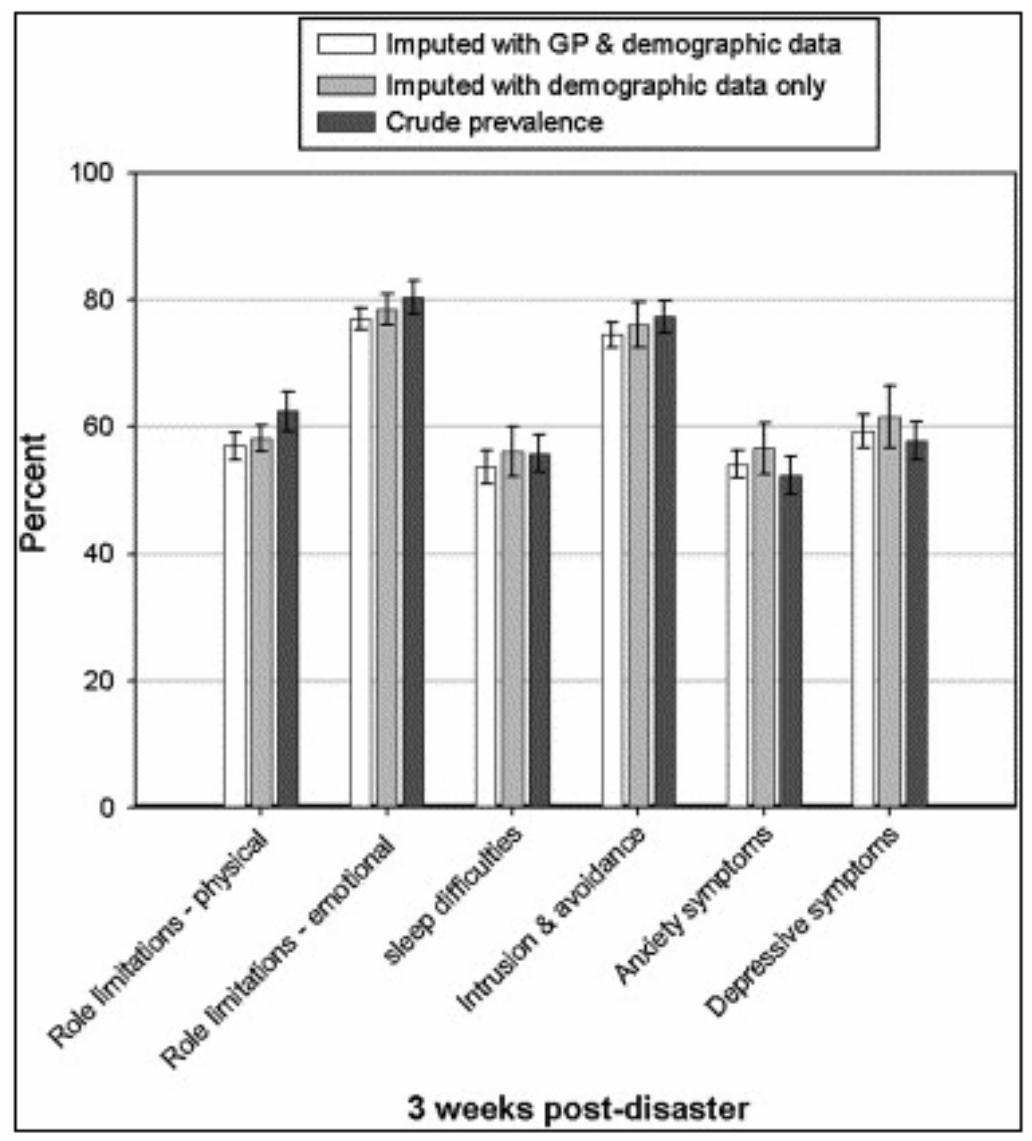

Figure 1. Prevalence estimates, crude and postimputation, with $95 \%$ confidence intervals for health problems reported in the survey; prevalence estimates were imputed with general practitioner and demographic data and with demographic data only 3 weeks after the firework disaster in Enschede, The Netherlands (May $13,2000)$.

\section{Discussion}

This study is unique in that we were able to estimate whether participants in a survey 3 weeks after a man-made disaster were representative of the entire cohort of affected residents on many aspects related to participation.

We observed a lower participation rate for men, young adults, and singles. This selection was observed previously in survivors of disasters 7,10 and 27 . In contrast to other studies 9 and 26, we observed a greater participation rate for immigrants. A possible reason is that even before the disaster, health education workers of immigrant background in Enschede had an outreach policy toward immigrants. These workers function as a "cultural bridge" between immigrants 
and health services. Health education workers actively motivated immigrants to participate in the study.

Our results show that there was selective participation in the survey. Survivors who reported more health problems before the disaster and those who had more distress postdisaster were more likely to participate in the survey. In addition, results suggest that survivors with more postdisaster distress were more likely to participate than those with predisaster distress. This group may have attributed their health problems to the disaster and therefore were more likely to participate in the survey. To our knowledge, no other disaster study examined whether their participants differed from all eligible survivors for (predisaster) health

characteristics. Two studies had predisaster data for health, but their predisaster study populations were not necessarily representative of all survivors; therefore, we have only some indication of selection 7 and 8 . Ginexi et al. (7) found that flood survivors with predisaster depression were more likely to be lost to followup postdisaster. Conversely, Phifer and Norris (8) did not observe a relation of postdisaster response to predisaster depression, anxiety, or general well-being.

Selective participation on the basis of disaster experience was not observed. Relocated residents (the most heavily exposed) were as likely to participate as nonrelocated residents. We cannot compare our data with other studies because we have no knowledge of other published data on disaster factors in relation to response. McFarlane et al. (29) suggested that those most affected, i.e., people with losses and injuries, might be underrepresented. This latter is plausible if survivors were not able to participate because of hospitalization. This selection is unlikely in our study because the majority of injured survivors were hospitalized for less than 3 weeks. In addition, those $(n<20)$ who were still hospitalized received a questionnaire.

Prevalence estimates measured in the survey were barely affected after multiple imputation with demographics and predisaster and postdisaster health factors. This was unexpected because we observed selective participation for these factors. Because existing correlations between all factors used in the imputation model were systematically in the same direction, we believe the multiple imputation model was adequate for predicting missing data caused by nonresponse (23). The reason for this unexpected finding probably is that biases were too small to affect prevalence estimates. Correlations between the questionnaire and GP data were low because participants reported more health problems on the questionnaire than they presented to the GP. Because the observed biases also were small, multiplication of two low correlations might have led to the finding of only minor differences between unimputed and imputed prevalence estimates.

Within the cohort, we had demographic data for all affected residents and GP data for about two thirds, including data from the predisaster period. From the literature, we know that demographic variables can be useful predictors of health status and therefore could be used for data imputation. Use of GP data was additional and new. Although $35 \%$ of these data were missing, this would only affect results if patients with GP data had different correlations between the questionnaire and GP data than those for whom GP data were not available. This is unlikely because reasons for nonparticipation among GPs were not related to health problems of individual patients. As expected, a high percentage of relocated residents had missing GP data because they had moved outside Enschede. Reanalysis showed that relocated residents did not have different selective participation in health clusters than nonrelocated residents, suggesting 
that inclusion of additional GP data from relocated residents would not have affected results.

With our high nonparticipation rate, we cannot exclude the possibility that selection was dependent on unobserved factors, which cannot be accounted for in multiple imputation. For example, we did not have educational level or income as socioeconomic status variables, whereas these variables often are associated with both health problems and participation 25 and 28. However, we had information on type of health insurance, which can be seen as a proxy for socioeconomic status in The Netherlands; being publicly insured is associated with a lower income level. Type of health insurance was not associated with participation rate, suggesting that use of another socioeconomic indicator would not have changed results. Although we had only one disaster-related characteristic for all survivors (relocation because of the disaster), this variable probably correlated highly with other disaster experiences (2).

In conclusion, 3 weeks after a man-made disaster, the observed selective participation in the health survey was not substantial enough to affect prevalence estimates of health problems in the survey. This conclusion emphasizes that selective participation does not always lead to bias in the outcome, and it is essential to calculate whether the observed selection actually leads to bias. Assuming the imputation model is correct and self-reported prevalence estimates were not an overestimation, the public health policy in Enschede, based on the observed estimates, was adequate. Because this is the first disaster study examining the magnitude of the bias for health- and disaster-related characteristics, we encourage other researchers of disaster surveys to collect information about these characteristics among nonresponders. We recommend that researchers in other countries with a similar GP registration system (the United Kingdom and Denmark) collect additional data through GPs after disasters to calculate selective participation in the survey. If additional data collection on health is not possible, we recommend that disaster studies at least use demographic variables from the Census or Registry Office to quantify their possible selection bias. Statistical techniques (weighting or multiple imputation) can help calculate bias on the outcome. Our results suggest that multiple imputation using only demographic variables might be adequate. When selection bias is present, use of such statistical techniques can improve the representativeness of the prevalence estimates of health problems and in this way support policy making to organize and improve health care in the aftermath of disasters.

This longitudinal study was part of the Health Monitor Survey Victims Firework Disaster Enschede and was performed under the authority of the Ministry of Health, Welfare and Sports in The Netherlands. Several research institutes cooperated in this surveillance program: The National Institute for Public Health and the Environment, The Institute for Psychotrauma, The Netherlands Institute for Health Services Research, and the Department of Youth Health Care of the Regional Health Authority, The Netherlands. The Regional Health Authority also was the coordinator of this program. The authors gratefully acknowledge the work of all people involved in designing, organizing, and analyzing the study; in particular, Petra MH ten Veen of The Netherlands Institute for Health Services Research and Hendriek Boshuizen of The National Institute for Public Health and the Environment. 


\section{References}

1 B.L. Green, J.D. Lindy, M.C. Grace, G.C. Glesers, A.C. Leonard and M. Korol et al., Buffalo Creek survivors in the second decade: Stability of stress symptoms, Am J Orthopsychiatry 60 (1990), pp. 43-54.

2 F.H. Norris, M.J. Friedman, P.J. Watson, C.M. Byrne, E. Diaz and K. Kaniasty, 60,000 Disaster victims speak: Part I. An empirical review of the empirical literature-1981-2001, Psychiatry 65 (2002), pp. 207-239.

3 F.H. Norris, M.J. Friedman and P.J. Watson, 60,000 Disaster victims speak: part II. Summary and implications of the disaster mental health research, Psychiatry 65 (2002), pp. 240-260.

4 B. van den Berg, L. Grievink, J. Yzermans and E. Lebret, Medically unexplained physical symptoms in the aftermath of disasters: A systematic review, Epidemiol Rev 27 (2005), pp. 92-106.

5 S. Galea, A. Nandi and D. Vlahov, The epidemiology of post-traumatic stress disorder after disasters, Epidemiol Rev 27 (2005), pp. 78-91.

6 P.G. Van der Velden, L. Grievink, R.J. Kleber, A.N. Drogendijk, A.J.R. Roskam and F.G.H. Marcelissen et al., Post-disaster mental health problems and the utilization of mental health services: A four-year longitudinal comparative study, Adm Policy Ment Health \& Ment Health Serv Res 33 (2006), pp. 279-288.

7 E.M. Ginexi, K. Weihs, S.J. Simmens and D.R. Hoyt, Natural disaster and depression: A prospective investigation of reactions to the 1993 Midwest Floods, Am J Community Psychol 28 (2000), pp. 495518.

8 J.F. Phifer and F.H. Norris, Psychological symptoms in older adults following natural disaster: Nature, timing, duration, and course, J Gerontol 44 (1989), pp. 207-217.

9 E.L. Khoury, G.J. Warheit, M.C. Hargrove, R.S. Zimmerman, W.A. Vega and A.G. Gil, The impact of hurricane Andrew on deviant behavior among a multi-racial/ethnic sample of adolescents in Dade County, Florida: A longitudinal analysis, J Trauma Stress 10 (1997), pp. 71-91.

10 F.H. Norris, A.D. Murphy, C.K. Baker and J.L. Perilla, Postdisaster PTSD over four waves of a panel study of Mexico's 1999 flood, J Trauma Stress 17 (2004), pp. 283-292.

11 J. Roorda, W.A.H.J. van Stiphout and R.R.R. Huijsman-Rubingh, Post-disaster health effects: Strategies for investigation and data-collection; experiences from the Firework disaster, $\mathrm{J}$ Epidemiol Community Health 58 (2004), pp. 982-987.

12 I. van Kamp, P.G. van der Velden, R.K. Stellato, J. Roorda, J. van Loon and R.J. Kleber et al., Physical and mental health shortly after a disaster: First results from the Enschede firework disaster study, Eur J Public Health 16 (2006), pp. 252-258.

13 C.J. Yzermans, G.A. Donker, J.J. Kerssens, A.J.E. Dirkzwager, R.J.H. Soeteman and P.M.H. ten Veen, Health problems of victims before and after disaster: A longitudinal study in general practice, Int J Epidemiol 34 (2005), pp. 820-826.

14 K.I. van der Zee and R. Sanderman, Het meten van de algemene gezondheidstoestand met de RAND-36: een handleiding [Measuring General Health With the RAND-36: A Manual], Noordelijk Centrum voor Gezondheidsvraagstukken, Groningen, The Netherlands (1993).

15 T.F. Meijman, A.H.G. de Vries-Griever, G. de Vries and R. Kampman, The Construction and Evaluation of a One-Dimensional Scale Measuring Subjective Sleep Quality. Heijmans Bulletin (HB0767), State University Groningen, Groningen, The Netherlands (1985).

16 D. Brom and R.J. Kleber, De Schok Verwerkings Lijst [The Dutch version of the Impact of Event Scale], Ned Tijdschr Psychol 40 (1985), pp. 164-168.

17 M.J. Horowitz, N. Wilner and W. Alvarez, The Impact of Event Scale: A measure of subjective stress, Psychosom Assess 41 (1979), pp. 209-218. 
18 E. van der Ploeg, T.M. Mooren, R.J. Kleber, P.G. van der Velden and D. Brom, Construct validation of the Dutch version of the Impact of Event Scale, Psychol Assess 16 (2004), pp. 16-26.

19 L.R. Derogatis, R.S. Lipman and L. Covi, SCL-90: An outpatient psychiatric rating scale, preliminary I, Psychopharmacol Bull 9 (1973), pp. 13-28.

20 W.A. Arrindell and J.H.M. Ettema, SCL-90: Handleiding bij een multidimensionele psychopathologie indicator [Manual for a Multidimensional Psychopathology Indicator], Swets \& Zeitlinger, Lisse (1986).

$21 \mathrm{H}$. Lamberts and M. Woods, International Classification of Primary Care, Oxford University, Oxford (1987).

22 M. Cardol, L. van Dijk, J.D. de Jong, D.H. de Bakker and G.P. Westert, Tweede nationale studie naar ziekten en verrichtingen in de huisartspraktijk. Huisartsenzorg: wat doet de poortwachter?, The Netherlands Institute for Health Services Research, Utrecht (2004).

23 D.B. Rubin, Multiple Imputation for Nonresponse in Surveys, Wiley, New York (1987).

24 Lazzeroni LG, Schenker N, Taylor JMG. Robustness of multiple imputation techniques to model misspecification. American Statistical Association's 1990 Proceedings of the Survey Research Methods Section. August 6-9th, Anaheim, CA 1990:260-265.

25 Boshuizen HC, Viet AL, Picavet HSJ, Botterweck A, van Loon AJM. Non-response in a survey of cardiovascular risk factors in the Dutch population: Determinants and resulting biases. Public Health. 2006;120:297-308.

26 R. de Graaf, R.V. Bijl, P. Smit, A. Ravelli and W.A. Vollebergh, Psychiatric and sociodemographic predictors of attrition in a longitudinal study: The Netherlands Mental Health Survey and Incidence Study (NEMESIS), Am J Epidemiol 152 (2000), pp. 1039-1047.

27 A.L. Dougall, H.B. Herberman, D.L. Delahanty, S.S. Inslicht and A. Baum, Similarity of prior trauma exposure as a determinant of chronic stress responding to an airline disaster, $\mathrm{J}$ Consult Clin Psychol 68 (2000), pp. 290-295.

28 A.J.M. Van Loon, M. Tijhuis, H.S.J. Picavet, P.G. Surtees and J. Ormel, Survey non-response in the Netherlands: Effects on prevalence estimates and associations, Ann Epidemiol 13 (2003), pp. 105110.

29 A.C. McFarlane, J.R. Clayer and C.L. Bookless, Psychiatric morbidity following a natural disaster: An Australian bushfire, Soc Psychiatry Psychiatr Epidemiol 32 (1997), pp. 261-268. 